\title{
Histamine concentration of gastric mucosa in Helicobacter pylori positive and negative children
}

\author{
D M M Queiroz, E N Mendes, G A Rocha, A J A Barbosa, A S T Carvalho, J R Cunha-Melo
}

Laboratory of Research in Bacteriology, Departments of Pathology, Pediatrics, and Surgery, Faculdade de Medicina,

Universidade Federal de Minas Gerais, Belo Horizonte, Minas Gerais, Brazil D M M Queiroz E N Mendes G A Rocha A J A Barbosa A S T Carvalho J R Cunha-Melo

Correspondence to: Dr D M M Queiroz, Laboratory of Research in Bacteriology, Av Alfredo Balena, 190/464 - Belo Horizonte, MG - Brazil, CEP 30.130

Accepted for publication 26 June 1990

\begin{abstract}
The histamine concentration was determined by enzymatic isotopic method in biopsy specimens of oxyntic mucosa from 37 children. Nineteen of the 37 had Helicobacter pylori associated gastritis ( 9 with duodenal ulcer). The histamine concentration in the $H$ pylori negative group was mean (SD) $54 \cdot 1$ (23.1) $\mu \mathrm{g} / \mathrm{g}$ fresh weight, and that in the $H$ pylori positive group was $26.3(14.2) \mu \mathrm{g} / \mathrm{g}(\mathrm{p}<0.01)$. There was also a significant difference between $\boldsymbol{H}$ pylori positive patients with duodenal ulcer $(19.8(6 \cdot 3)$ $\mu \mathrm{g} / \mathrm{g}$ ) and those without ulcer (31.4 (17.9) $\mu \mathrm{g} / \mathrm{g})$ $(\mathbf{p}<0.05)$. These results suggest that $H$ pylori positive patients, especially those with duodenal ulcer, have reduced 'stored' histamine, perhaps because of increased histamine liberation.
\end{abstract}

The aetiology and pathogenesis of duodenal ulceration are not fully understood. It is currently accepted that peptic ulceration arises from a disturbance in the balance between acid production and mucosal resistance. ${ }^{1}$ A number of features are thought to be important in the pathogenesis of duodenal ulcer disease but clinical and epidemiological data now suggest that Helicobacter pylori plays a major role in most duodenal ulcer patients. ${ }^{2-5}$ In fact, the microorganism has been observed in up to $100 \%$ of subjects with this disorder and it can be eliminated by antibiotic treatment, leading to complete healing in some cases. ${ }^{4}$ Nevertheless, the mechanism by which the micro-organism promotes ulcer formation is uncertain.

Levi et al recently proposed that urease pro-

believe children are a suitable population for duodenal ulcer study because factors such as smoking, alcohol, and drugs, which are important in modifying expression of the disease in adults, are not present among them. Furthermore, we are not aware of any other study evaluating the histamine concentration of gastric mucosa in children.

\section{Patients and methods}

This project was approved by the Ethics Committee of Hospital das Clínicas, Universidade Federal de Minas Gerais, Brazil, and informed consent to the study was obtained from the parents of all the patients.

\section{STUDY SUBJECTS}

Thirty seven patients ( 27 boys) undergoing endoscopy for investigation of upper abdominal pain and who did not have a history of smoking or underlying disorders were included in the study. None had received non-steroidal anti-inflammatory drugs, histamine $\mathrm{H}_{2}$ receptor antagonists, or any other medication for at least 30 days before the study. Their ages ranged from 1 to 16 years (mean age $\mathbf{9 . 2}$ years). Nineteen of the patients had $H$ pylori associated gastritis. In this group nine children had endoscopically proved duodenal ulcer (eight boys, mean age 12.4 years) and 10 did not ( 8 boys, mean age $9 \cdot 0$ years).

Endoscopy was performed either under general anaesthesia or sedation (diazepam and pethidine) and local anaesthesia (lignocaine). The biopsy forceps were disinfected with $70 \%$ ethanol.

Biopsy specimens were collected from the mid region of the greater curvature of the gastric body for histamine determination, culture, and histology, and from the lesser curvature of the antrum for culture,' preformed urease test, ${ }^{12}$ carbolfuchsin staining, ${ }^{13}$ and histological examination. ${ }^{1+}$ with duodenal ulcer fell after eradication of $H$ pylori with antibiotics.

If increased acid secretion is linked to $H$ pylori in the pathogenesis of duodenal ulcer disease the amount of histamine in oxyntic mucosa of $H$ pylori positive and negative patients with and without duodenal ulcer should be measured, because histamine has been proposed as the final common mediator for all parietal cell secretagogues. ${ }^{9-11}$ We therefore determined the histamine concentration in oxyntic mucosa of $H$ pylori positive and negative children. We

\section{HISTAMINE ANALYSIS}

Three fragments taken from oxyntic mucosa were used for histamine determination. They were immediately frozen and were stored in liquid nitrogen until they were processed.

Histamine was extracted by slight modification

\section{EXTRACTION PROCEDURE}


of the method of Snyder et al. ${ }^{15}$ The fragments were weighed while thawing, immediately immersed in $0 \cdot 1 \mathrm{M}$ phosphate buffer $\mathrm{pH} 7 \cdot 9(1 \mathrm{~g} / 20$ $\mathrm{ml}$ ) in a plastic tube, homogenised with a Thomas teflon pestle tissue homogeniser (size 0, Thomas Scientific, Swedesboro, NJ, USA), and heated for 10 minutes in boiling water. After centrifugation at $5000 \mathrm{rpm}$ at $4^{\circ} \mathrm{C}$ for 10 minutes, the supernatant was lyophilised.

\section{ASSAY}

Histamine was assayed in dry residue suspended in $100 \mu \mathrm{l}$ of $0.1 \mathrm{M}$ phosphate buffer, $\mathrm{pH} \mathrm{7.9}$. Samples $(10 \mu \mathrm{l})$ were incubated at $37^{\circ} \mathrm{C}$ for 90 minutes in $1.5 \mathrm{ml}$ Eppendorf tubes with $35 \mu \mathrm{l}$ of reagent that contained (per $\mathrm{ml}$ ) $0.05 \mathrm{M}$ sodium phosphate buffer, $12 \mu \mathrm{l}$ of a rat kidney histamine methyltransferase enzyme preparation, ${ }^{16}$ and 10 $\mu \mathrm{l}$ of $20 \mu \mathrm{Ci} / \mathrm{ml}$ solution of $\mathrm{S}-\left(\right.$ methyl $\left.^{-14} \mathrm{C}\right)$ adenosyl-L-methionine (specific activity $55 \mathrm{mCi}$ / $\mathrm{mmol}$ ). The reaction was stopped by the addition of $20 \mu \mathrm{l}$ of $2 \% \mathrm{~N}$-methylhistamine dihydrochloride (1:4 methylhistamine dihydrochloride, Sigma Chemical Co, St Louis, USA) in $1.5 \mathrm{M}$ perchloric acid. A solution containing $20 \mu$ lof $10 \mathrm{~N} \mathrm{NaOH}$ and $500 \mu \mathrm{l}$ of a mixture of isoamyl alcohol and toluene $(20: 80)$ was then added to each tube. The tubes were capped, shaken for 10 minutes, and centrifuged for 60 seconds on a Beckman Microfuge (Beckman Instruments). A $300 \mu \mathrm{l}$ sample of the upper organic layer was transferred to $5 \mathrm{ml}$ of scintillation fluid for assay of radioactivity. The results were expressed as cpm and the histamine concentration per sample was calculated, based on a standard curve constructed with known amounts of histamine.

\section{STATISTICAL METHODS}

Statistical analysis was performed by Student's two tailed $t$ test or the Mann-Whitney U test when the frequency distribution of the mucosal histamine contents in one group diverged considerably from the other. Differences were taken as significant when $\mathrm{p}<0.05$.

\section{Results}

$H$ pylori NEGATIVE GROUP

In 18 children who were not shown to have duodenal ulcer at endoscopy, $H$ pylori was not

Histological findings in the gastric mucosa of Helicobacter pylori $(H P)$ positive and negative children with and without duodenal ulcer $(D U)$

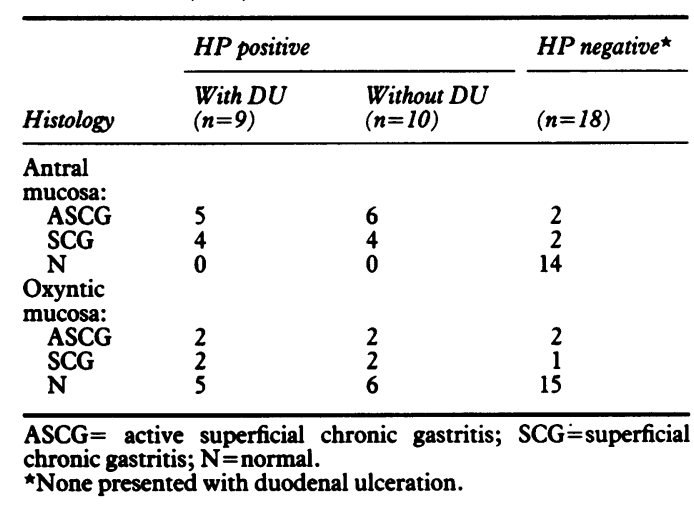

isolated and was not observed on histological sections of antral and oxyntic mucosa. Moreover, the urease test was negative and spiral microorganisms were not seen on carbofuchsin stained smears of antral mucosa. Histopathological analysis showed normal antral mucosa in 14 patients. Three children showed antral and oxyntic chronic gastritis and one with antral gastritis only (Table). In this $H$ pylori negative group, the oxyntic mucosa histamine content was mean (SD) $54.09(23.09) \mu \mathrm{g} / \mathrm{g}$ fresh weight. With regard to sex, there was no significant difference between the mucosal histamine content of male $((\mathrm{n}=11) 54 \cdot 19(26 \cdot 22) \mu \mathrm{g} / \mathrm{g})$ and female $((\mathrm{n}=7)$ $49 \cdot 22(17 \cdot 87) \mu \mathrm{g} / \mathrm{g})$ patients $(\mathrm{p}=0 \cdot 49)$.

\section{$H$ pylori POSITIVE GROUP}

This group included nine children with and 10 without duodenal ulcer. In the latter group, $H$ pylori was isolated from antral and oxyntic mucosa and spiral micro-organisms were seen on histological sections of antral mucosa. The urease test was positive in all the patients.

The histopathological findings in antral and oxyntic mucosa from these patients are given in the Table. All children showed antral superficial chronic gastritis but oxyntic gastritis was observed in only $42 \cdot 1 \%$ of them.

The mucosal histamine concentration of the $H$ pylori positive patients was mean (SD) $26 \cdot 28$ $(14 \cdot 19) \mu \mathrm{g} / \mathrm{g}$. There was a significant difference between this group and $H$ pylori negative patients $(\mathbf{p}<0.01)$. In duodenal ulcer patients, the mucosal histamine content was mean (SD) 19.75 $(6.30) \mu \mathrm{g} / \mathrm{g}$ and in $H$ pylori positive patients without duodenal ulcer disease it was 31.44 $(17 \cdot 90) \mu \mathrm{g} / \mathrm{g}$. Duodenal ulcer patients had significantly lower concentrations of mucosal histamine than $H$ pylori positive patients without ulcers $(\mathrm{p}<0.05)$. A significant difference was also observed between $H$ pylori negative patients and the following two groups: (a) $H$ pylori positive children without duodenal ulcer $(\mathrm{p}=0.01)$ and $(\mathrm{b})$ duodenal ulcer patients $(\mathrm{p}<0.01)$.

\section{Discussion}

It has been reported that relatively high histamine values are found in the glandular region of the stomach in all animal species. ${ }^{17}$ In man, gastric mucosa histamine is stored in the mast cells, which are most abundant in the body and located close to or adjacent to parietal cells. ${ }^{117}$

Histamine has long been recognised as a gastric secretagogue, but only since the introduction of $\mathrm{H}_{2}$ blockers has its physiological role in regulating gastric acid secretion been unquestionable. ${ }^{18}$ Moreover, the $\mathrm{H}_{2}$ blockers also inhibit acid secretion stimulated by gastrin ${ }^{19}$ and by vagal nerves..$^{20}$ Because of this it has been proposed that histamine is the final mediator of gastric acid secretion. ${ }^{1011}$ In fact, infusion of pentagastrin, a synthetic analogue of gastrin, produces gastric acid secretion and reduces the mucosal histamine concentration. ${ }^{178}$ In addition, during pentagastrin infusion, both gastric juice and plasma histamine values increase. ${ }^{910} 17$ Gastrin evokes a histamine release of such a magnitude that it is 
sufficient to explain the whole gastric acid stimulatory effects of this peptide ${ }^{917}$ Furthermore, it was also shown that electrical stimulation of the vagal nerves elicits an immediate histamine release. ${ }^{21}$ It seems, however, that vagal stimulation can also induce acid secretion by another more direct mechanism. ${ }^{21}$

It is well established that duodenal ulcer disease is generally associated with gastric hypersecretion and hyperchlorhydria. ${ }^{22}$ Hyperacidity is, without doubt, an important physiological abnormality in most patients. Moreover, patients with chronic duodenal ulceration have significantly lower concentrations of gastric mucosal histamine than control subjects. ${ }^{23-25}$ It has been suggested that this finding may be related to a state of high mobilisation of endogenous mucosal histamine with depletion of its stores. ${ }^{1624}$

In this study we found that $H$ pylori positive children, both with or without duodenal ulcer disease, had significantly lower oxyntic mucosal histamine concentrations than $H$ pylori negative patients. We also showed that there is a significant difference between $H$ pylori positive children with and without duodenal ulcer. This difference could be explained by the fact that duodenal ulcer patients show greater density of $H$ pylori than $H$ pylori positive patients without duodenal ulcer disease, ${ }^{26}$ which could be associated with a greater stimulus to gastric acid secretion. As the low endogenous histamine concentration may be an indirect reflex of an increased acid secretion, $H$ pylori seems to be associated with high acid secretion. In fact, it was recently shown that $H$ pylori positive patients have increased serum gastrin values that could result in increased acid secretion. Inappropriate hypergastrinaemia cannot be incriminated as the only cause of the increased acid secretion, however, as this can also be stimulated by the vagal nerves as well as by locally released histamine. ${ }^{1011171821}$ Thus, besides bacterial urease, other bacterial products such as toxins may promote gastric secretion not only by gastrin but also by direct action on histamine release or by direct stimulation of the vagal nerves. In duodenal ulcer patients the constant and strong stimulus to gastric secretion could lead to an exhaustion of mucosal histamine content that could culminate in reduced gastric acid secretion and therefore duodenal healing. The periods of spontaneous exacerbation and remission, characteristically observed in duodenal ulcer disease, could be explained by this mechanism.

We think that although there are still many unanswered questions, there is evidence suggesting that $H$ pylori is involved in the pathogenesis of duodenal ulceration by two different mechanisms - firstly by colonising areas of gastric metaplasia in the duodenum, causing active inflammation that may render the mucosa more liable to ulceration ${ }^{27}$ and secondly by producing increased acid secretion that leads to a low intraduodenal $\mathrm{pH}$, via gastrin or other gastric secretagogues. The mucosal reparative processes do not operate normally in the presence of hyperacidity.

In conclusion, the present study shows that $H$ pylori positive children with and without duodenal ulceration have depleted oxyntic mucosal histamine stores. This finding needs to be confirmed in adults as well as in a larger group of children. Furthermore, we are evaluating gastric mucosal histamine values before and after eradication of $H$ pylori to test our hypothesis that this micro-organism is involved in gastric histamine metabolism.

This work was supported by grants from CNPq, FINEP, and FAPEMIG (Brazil).

1 Baron JH. Current views on pathogenesis of peptic ulcer. Scand f Gastroenterol 1982; 17: 1-10.

2 Graham DY. Campylobacter pylori and peptic ulcer disease. Gastroenterology 1989; 96: 615-25.

3 Dooley CP, Cohen H. The clinical significance of Campylobacter pylori. Ann Intern Med 1988; 108: 70-9.

4 Marshall BJ, Goodwin CS, Warren JR, et al. Prospective double-blind trial of duodenal ulcer relapse after eradication of Campylobacter pylori. Lancet 1989; ii: 1467-9.

5 Queiroz DMM, Barbosa AJA, Mendes EN et al. Distribution of Campylobacter pylori and gastritis in the stomach of patients with and without duodenal ulcer. Am $\mathcal{F}$ Gastroenterol 1988; 83: 1368-70.

6 Levi S, Beardshall K, Haddad G, Playford R, Ghosh P, Calam J. Campylobacter pylori and duodenal ulcers: the gastrin link. Lancet 1989; i: 1167-8.

7 Oderda G, Vaira D, Holton J, Ainley C, Altare F, Ansaldi N. Amoxycillin plus tinidazole for Campylobacter pylori gastritis in children: assessment by serum IgG antibody, pepsinogen I, and gastrin levels. Lancet 1989 ; i: $690-2$.

8 McColl KEL, Fullarton GM, El Nujumi AM, Macdonald AM, Brown IL, Hilditch TE. Lowered gastrin and gastric acidity after eradication of Campylobacter pylori in duodenal ulcer. Lancet 1989; ii, 499-500.

9 Man WK, Ingoldby CJH, Spencer J. Is pentagastrinstimulated secretion mediated by histamine? Gut 1984; 25 : 965-70.

10 Waldum HL, Sandvick AK. Histamine and the stomach. Scand 7 Gastroenterol 1989; 24: 130-9.

11 Code CF. Reflections on histamine gastric secretion and the $\mathrm{H} 2$ receptor. N Engl F Med 1977; 296: 1459-62.

12 McNulty CAM, Watson DM. Spiral bacteria of the gastric antrum. Lancet 1984; i: 1068-9.

13 Rocha GA, Queiroz DMM, Mendes EN, Lage AP, Barbosa AJA. Simple carbolfucshin staining for showing $C$ pylori and other spiral bacteria in gastric mucosa. F Clin Pathol 1989; 42: $1004-5$.

14 Whitehead R, Truelove SC, Gear MWL. The histological diagnosis of chronic gastritis in fibreoptic gastroscope biopsy specimens. F Clin Pathol 1972; 25: 1-11.

15 Snyder SH, Baldessarini RJ, Axelrod J. A sensitive and specific enzymatic isotopic assay for tissue histamine. $\mathcal{F}$ Pharmacol Exp Therap 1966; 153: 544-9.

16 Shaff RE, Beaven MA. Increased sensitivity of the enzymatic isotopic assay of histamine measurement of histamine in isotopic assay of histamine measurement of histam
plasma and serum. Anal Biochem 1979; 94: 425-30.

17 Man WK, Saunders JH, Ingoldby C, Spencer J. Effect of pentagastrin on histamine output from the stomach in patients with duodenal ulcer. Gut 1981; 22: 916-22.

18 Sandvik AK, Waldum HL, Kleveland PM, Schulze Sognen B. Gastrin produces an immediate and dose-dependent histamine release preceding acid secretion in the totally isolated vascularly perfused rat stomach. Scand $\mathcal{F}$ Gastroenterol 1987 ; 22: 803-8.

19 Black JW, Durant CJ, Ganellin CR, Parsons EM. Definition and antagonism of histamine H2-receptors. Nature 1972; 236: $385-90$.

20 Grossman MI, Konturek SJ. Inhibition of acid secretion in dog by metiamide, a histamine antagonist acting on $\mathrm{H} 2$ recepby metiamide, a histamine antagonist

21 Sandvik AK, Kleveland PM, Waldum HL. Muscarinic M2 stimulation releases histamine in the totally isolated, vascularly perfused rat stomach. Scand $\mathcal{F}$ Gastreoenterol 1988; 23: $1049-56$

22 Feldman M, Richardson CT. Total 24-hour gastric acid secretion in patients with duodenal ulcer: comparison with normal subjects and effects of cimetidine and parietal cell vagotomy. Gastroenterology 1986; 90: 540-4

23 Peden NR, Calachan H, Shepherd DM, Wormsley KG. Gastric mucosal histamine and histamine methyltransferase in patients with duodenal ulcer. Gut 1982; 23:58-62.

24 Troidl WL, Rohde H, Hafner G, Ronzheimer M. Histamine and peptic ulcer: a prospective study of mucosal histamine and peptic ulcer: a prospective study of mucosal histamine subjects suffering from various gastrointestinal diseases. subjects suffering from variou
$K$ lin $W$ schr $1976 ; 54: 947-56$.

25 Thon KP, Lorenz W, Ohmann C, Weber D, Rohde H, Roher HD. Sample taking problems in measuring actual histamine levels of human gastroduodenal mucosa: specific and general relevance in clinical trials on peptic ulcer pathogenesis and selective proximal vagotomy. Gut $1985 ; 26$ : 1165-78.

26 Queiroz DMM, Quintão JGA, Mendes EN, Rocha GA, Lage AP, Barbosa AJA. Density of Campylobacter pylori is enhanced on antral mucosa of patients with duodenal ulcer. Klin Wschr 1989; 67 (Suppl XVIII): 57.

27 Goodwin CS. Duodenal ulcer, Campylobacter pylori, and the 'leaking roof' concept. Lancet 1988; ii: 1467-9. 